\title{
Fucoxanthin and its metabolite, fucoxanthinol, suppress adipocyte differentiation in 3T3-L1 cells
}

\author{
HAYATO MAEDA $^{1}$, MASASHI HOSOKAWA ${ }^{1}$, TOKUTAKE SASHIMA ${ }^{2}$, \\ NOBUYUKI TAKAHASHI ${ }^{3}$, TERUO KAWADA ${ }^{4}$ and KAZUO MIYASHITA ${ }^{1}$ \\ ${ }^{1}$ Faculty of Fisheries Sciences, ${ }^{2}$ Creative research Institute, Hokkaido University, Hakodate, Hokkaido 041-8611; \\ ${ }^{3}$ Department of Cell Physiology, National Institute of Physiological Science (NIPS), Okazaki 444-8585; \\ ${ }^{4}$ Graduate School of Agriculture, Kyoto University, Uji, Kyoto 611-0011, Japan
}

Received January 16, 2006; Accepted March 9, 2006

\begin{abstract}
Fucoxanthin is a major carotenoid found in edible seaweed such as Undaria pinnatifida and Hijikia fusiformis. We investigated the suppressive effects of fucoxanthin and its metabolite, fucoxanthinol, on the differentiation of 3T3-L1 preadipocytes to adipocytes. Fucoxanthin inhibited intercellular lipid accumulation during adipocyte differentiation of 3T3-L1 cells. Furthermore, fucoxanthin was converted to fucoxanthinol in 3T3-L1 cells. Fucoxanthinol also exhibited suppressive effects on lipid accumulation and decreased glycerol-3phosphate dehydrogenase activity, an indicator of adipocyte differentiation. The suppressive effect of fucoxanthinol was stronger than that of fucoxanthin. In addition, in 3T3-L1 cells treated with fucoxanthin and fucoxanthinol, peroxisome proliferator-activated receptor $\gamma(\operatorname{PPAR} \gamma)$, which regulates adipogenic gene expression, was down-regulated in a dosedependent manner. These results suggest that fucoxanthin and fucoxanthinol inhibit the adipocyte differentiation of 3T3-L1 cells through down-regulation of PPAR $\gamma$. Fucoxanthinol had stronger suppressive effects than fucoxanthin on adipocyte differentiation in 3T3-L1 cells.
\end{abstract}

\section{Introduction}

Adipocytes have an important role in energy homeostasis. Adipose tissue stores energy in the form of lipid and releases fatty acids in response to nutritional signals or energy insufficiency (1). Further, adipocytes have endocrine functions by secreting hormones and factors that regulate physiological functions, such as immune response, insulin sensitivity and food intake (2,3). Excessive fat accumulation in the body and white adipose tissue causes obesity and results in an increased risk of many serious diseases, including type II diabetes,

Correspondence to: Dr M. Hosokawa, Faculty of Fisheries Sciences, Hokkaido University, Hakodate, Hokkaido 041-8611, Japan

E-mail: hoso@fish.hokudai.ac.jp

Key words: fucoxanthinol, fucoxanthin, 3T3-L1 cells, differentiation, adipocyte, peroxisome proliferator-activated receptor $\gamma$, glycerol-3-phosphate dehydrogenase hypertension and heart disease. The regulation of adipose differentiation has been studied for the prevention of life stylerelated diseases $(4,5)$ because adipose tissue development is closely related to adipocyte differentiation.

Carotenoids have beneficial health effects such as provitamin A activity, immune response modulation, and anticarcinogenic activity (6). Fucoxanthin (Fig. 1), which has a unique structure including an allenic bond and a 5,6-monoepoxide in the molecule (7), is a major marine carotenoid found in edible seaweeds such as Undaria pinnatifida, Hijikia fusiformis and Sargassum fulvellum. In Southeast Asian countries, some seaweeds containing fucoxanthin are often used as a food source. Fucoxanthin has anti-carcinogenic effects $(8,9)$, apoptotic effects in cancer cells (10-13), antiinflammatory effects (14), and radical scavenging activity (15). We recently reported that dietary fucoxanthin suppressed weight gain of white adipose tissue in an obese mouse model, KK-Ay (16). Because most body fat is stored in white adipose tissue, decreasing white adipose tissue weight by fucoxanthin might be a very effective approach for preventing and/or alleviating obesity. The effects of fucoxanthin and its metabolite on the cellular mechanisms responsible for adipocyte differentiation, however, are unknown.

In the present study, we investigated the effects of fucoxanthin and its metabolite, fucoxanthinol (Fig. 1), on the differentiation of a murine 3T3-L1 preadipocyte cell line. In addition, the incorporation and metabolism of fucoxanthin in 3T3-L1 cells were analyzed. Fucoxanthin suppressed intracellular lipid accumulation and glycerol-3-phosphate dehydrogenase (GPDH) activity induced during adipose differentiation in 3T3-L1 cells. Some of the fucoxanthin incorporated into 3T3-L1 cells was converted to the metabolite, fucoxanthinol. Fucoxanthinol suppressed 3T3-L1 cell differentiation, accompanied by a down-regulation of peroxisome proliferator-activated receptor $\gamma(\operatorname{PPAR} \gamma)$. Fucoxanthinol had greater suppressive effects on 3T3-L1 cell differentiation than fucoxanthin.

\section{Materials and methods}

Materials. Mouse 3T3-L1 (CCL-92.1) preadipocytes were obtained from the American Type Culture Collection (Rockville, CT, USA). Fetal bovine serum (FBS) and Dulbecco's modified Eagle's medium (DMEM) were purchased 


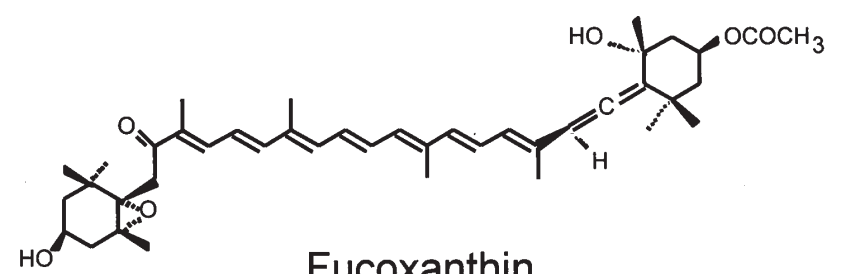

Fucoxanthin

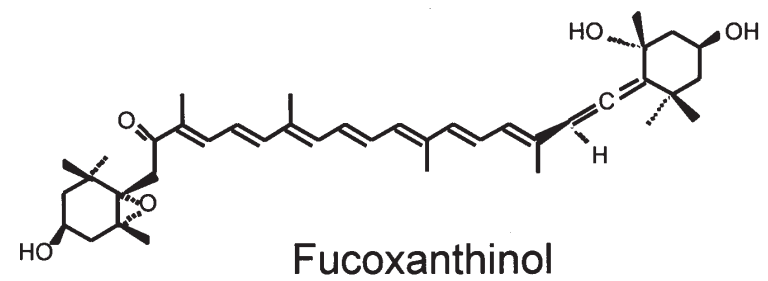

Figure 1. Structure of fucoxanthin and fucoxanthinol.

from Asahi Techno Glass Co., Ltd. (Funabashi, Chiba, Japan) and Nissui Pharmaceutical Co., Ltd. (Ueno, Tokyo, Japan), respectively. Fucoxanthin was isolated from brown alga, Undaria pinnatifida, as previously described (13). Fucoxanthinol was prepared from fucoxanthin by hydrolysis with porcine pancreas lipase, Type II (Sigma, St. Louis, MO, USA). Two milligrams of fucoxanthin and $10 \mathrm{mg}$ of taurocholic acid sodium salt were dissolved in a small volume of methanol, and the solvent was dried under nitrogen. Then, $20 \mathrm{mg}$ lipase (Sigma) in $8 \mathrm{ml}$ of potassium phosphate buffer (0.1 M, pH 7.0) were added to the residue and mixed. After incubation at $37^{\circ} \mathrm{C}$ for $2 \mathrm{~h}, 1 \mathrm{ml}$ of methanol was added to reaction mixture. Then, two milliliters of diethyl ether was added, and fucoxanthinol was extracted into the diethyl ether phase. The extracted fucoxanthinol was further purified by HPLC. Troglitazone was purchased from Cayman Chemical Company (Ann Arbor, Michigan, USA). PPAR $\gamma$ and $\beta$-Actin antibody were purchased from Santa Cruz Biotechnology (Santa Cruz, California, USA).

3T3-L1 culture. 3T3-L1 cells were cultured in DMEM with $10 \% \mathrm{FBS}, 100 \mathrm{U} / \mathrm{ml}$ penicillin and $100 \mu \mathrm{g} / \mathrm{ml}$ streptomycin at $37^{\circ} \mathrm{C}$ in a humidified atmosphere of $95 \%$ air and $5 \% \mathrm{CO}_{2}$. After 3T3-L1 cells reached confluence, they were incubated for an additional $24 \mathrm{~h}$. Then, adipocyte differentiation of 3T3-L1 preadipocytes was initiated using differentiation medium I containing $10 \mu \mathrm{g} / \mathrm{ml}$ insulin, $0.5 \mathrm{mM}$ isobutylmethylxanthine and $0.1 \mu \mathrm{M}$ dexamethazone for $48 \mathrm{~h}$. The medium was then replaced with DMEM containing $5 \mu \mathrm{g} / \mathrm{ml}$ insulin (differentiation medium II), and changed to fresh medium every 2 days. Fucoxanthin and fucoxanthinol were added to differentiation medium II as ethanol solution. The final concentration of ethanol was adjusted to $0.1 \%$ so as not to affect cell growth. The cytotoxicity of fucoxanthin and fucoxanthinol on 3T3-L1 cells was determined using WST-1 assay (17).

Oil Red-O staining. Intercellular lipid accumulation was measured by Oil Red-O staining during adipocyte differentiation (18). 3T3-L1 cells were incubated in differentiation medium II containing carotenoid for $120 \mathrm{~h}$. After incubation, cells were washed twice with PBS and fixed in a $10 \%$ formalin-containing PBS solution at $4^{\circ} \mathrm{C}$ for $1 \mathrm{~h}$. The fixed cells were washed twice with distilled water and then stained using $0.3 \%$ Oil Red-O for $15 \mathrm{~min}$ at room temperature. Excess Oil Red-O dye was washed with distilled water. Stained oil droplets in 3T3-L1 cells were extracted with isopropanol and then the absorbance of the extracts was measured at $490 \mathrm{~nm}$. In addition, the absorbance of the extracts from 3T3-L1 cells without Oil Red-O dye staining after incubation with carotenoid treatment was measured. The difference in absorbance between the isopropanol extracts from cells with and without Oil red-O dye was calculated. Results were represented as a relative percentage of differentiated 3T3-L1 cells without carotenoid treatment (control).

HPLC analysis. Fucoxanthin and fucoxanthinol extracted with chloroform:methanol $(1: 2, \mathrm{v} / \mathrm{v})$ from $3 \mathrm{~T} 3-\mathrm{L} 1$ cells were analyzed using a high performance liquid chromatograph (HPLC, Hitachi, Tokyo, Japan) system equipped with a Lichrospher@RP-18e column (4x250 mm, Merck). The mobile phase used was methanol/acetonitrile $(7: 3, \mathrm{v} / \mathrm{v})$ at a flow rate of $1.0 \mathrm{ml} / \mathrm{min}$ and carotenoids were detected at $450 \mathrm{~nm}$ by a diod array detector (L7455 type, Hitachi). The amount of fucoxanthin and fucoxanthinol were quantified from their peak area by use of a standard curve with purified fucoxanthin and fucoxanthinol.

Measurement of GPDH activity. Glycerol phosphate dehydrogenase (GPDH, EC 1.1.1.8) activity (19) was measured using a commercial assay kit (Hokudo Co., Ltd., Sapporo, Hokkaido, Japan) according to the manufacturer's instructions. 3T3-L1 cells incubated in differentiation medium II containing carotenoid for $120 \mathrm{~h}$ were washed twice with PBS and dissolved in enzyme extract solution. Then, the cell lysate was homogenized by supersonic waves on ice, and centrifuged at $2,800 \mathrm{~g}$ for $5 \mathrm{~min}$ at $4^{\circ} \mathrm{C}$. The supernatant was used for the measurement of GPDH activity. The protein content was measured with a DC protein assay kit (Bio-Rad Laboratories, Inc., Tokyo, Japan).

Western blot analysis. 3T3-L1 cells were incubated in differentiation medium II containing carotenoid for $120 \mathrm{~h}$. Cells were lysed with cold RIPA buffer ( $\mathrm{pH}$ 7.4) containing $20 \mathrm{mM}$ Tris- $\mathrm{HCl}, 150 \mathrm{mM} \mathrm{NaCl}, 1 \% \mathrm{NP}-40,0.5 \%$ sodium deoxycholate, $0.1 \%$ sodium dodecyl sulphate (SDS), $0.1 \mathrm{mg} / \mathrm{ml}$ phenylmethylsulphonyl fluoride, $50 \mu \mathrm{g} / \mathrm{ml}$ aprotinin and $1 \mathrm{mM}$ $\mathrm{Na}_{3} \mathrm{VO}_{4}$. Cell lysates were centrifuged at $13,000 \mathrm{~g}$ for $20 \mathrm{~min}$ at $4{ }^{\circ} \mathrm{C}$, and supernatant ( $30 \mu \mathrm{g}$ protein/lane) was separated by $10 \%$ SDS-polyacrylamide gel electrophoresis. Proteins were transferred to polyvinylidene difluoride membrane. The membrane was incubated with an antibody against PPAR $\gamma$ for $1 \mathrm{~h}$ and then with secondary antibody rabbit IgG-conjugated horseradish peroxidase (Santa Cruz Biotechnology) for $1 \mathrm{~h}$ at room temperature. The membranes were treated with reagents in the chemiluminescence detection kit (ECL system, Amersham Pharmacia Biotech, Piscataway, NJ, USA) according to the manufacturer's instructions. B-Actin was used as the control with the anti-B-Actin antibody.

Statistical analysis. Statistical significance of differences was evaluated by Student's t-test. 


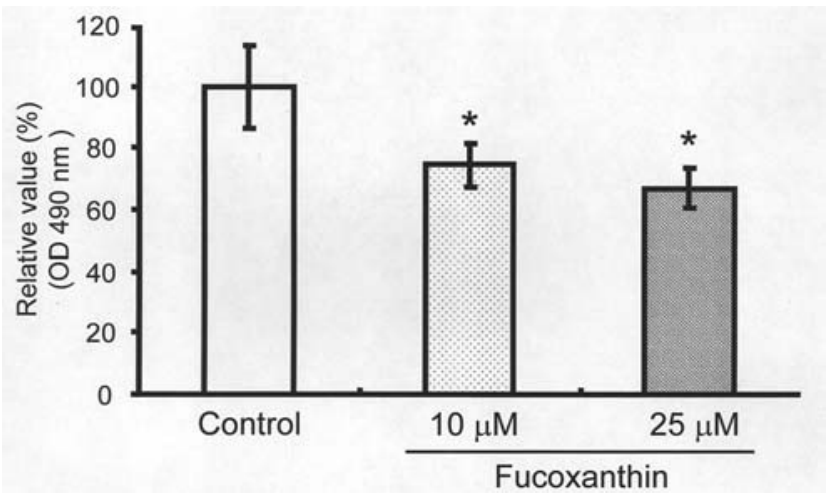

Figure 2. Effect of fucoxanthin on lipid accumulation of 3T3-L1 cells during adipocyte differentiation. 3T3-L1 cells $\left(5 \times 10^{3}\right.$ cells in 96-well plates) were differentiated to adipocytes as described in Materials and methods. 3T3-L1 cells were treated with fucoxanthin in differentiation medium II for $120 \mathrm{~h}$. The intercellular lipid accumulation was determined by Oil Red-O staining. The values $(n=3)$ are expressed as absorbance at $490 \mathrm{~nm}$. *Significantly different from the control value $(\mathrm{P}<0.01)$.

\section{Results}

Effect of fucoxanthin on lipid accumulation during adipocyte differentiation. The effect of fucoxanthin on lipid accumulation during 3T3-L1 differentiation was examined using Oil Red-O dye staining, which indicates intercellular lipid accumulation. Fucoxanthin attenuated the Oil Red-O staining level (Fig. 2). The Oil Red-O staining level of 3T3-L1 cells treated with $15 \mu \mathrm{M}$ fucoxanthin for $120 \mathrm{~h}$ was reduced to $70 \%$ that of differentiated 3T3-L1 adipocytes.

We also measured the viability of 3T3-L1 cells treated with fucoxanthin. Fucoxanthin was not cytotoxic to 3T3-L1 cells after $120 \mathrm{~h}$ incubation at $15 \mu \mathrm{M}$ (data not shown).

Uptake and conversion of fucoxanthin in 3T3-L1 cells. Fucoxanthin added to the culture medium was incorporated into 3T3-L1 cells after 24-h incubation (Fig. 3). Fucoxanthinol, which is a deacetylated derivative of fucoxanthin, was also detected in the cells (Fig. 3) but not in the culture medium (data not shown). When $10 \mu \mathrm{M}$ fucoxanthin was added to differentiation media II , the fucoxanthin level in the cells was $1.2 \mu \mathrm{g} / \mathrm{mg}$ protein after $24-\mathrm{h}$ incubation and did not remarkably change until after 57-h incubation. On the other hand, the fucoxanthinol level increased to $4.9 \mu \mathrm{g} / \mathrm{mg}$ protein after $57-\mathrm{h}$ incubation from $0.9 \mu \mathrm{g} /$ protein after $24-\mathrm{h}$ incubation. We also measured fucoxanthinol uptake by 3T3-L1 cells. Intracellular fucoxanthinol levels reached $5.8 \mu \mathrm{g} / \mathrm{mg}$ protein after 24-h incubation and increased for up to $48 \mathrm{~h}$. The accumulation of fucoxanthinol in 3T3-L1 cells treated with fucoxanthinol was markedly higher than the accumulation of fucoxanthin and fucoxanthinol together in cells treated with fucoxanthin.

Effect of fucoxanthinol on adipocyte differentiation. Because some of the fucoxanthin incorporated into 3T3-L1 cells was converted to fucoxanthinol, we examined the suppressive effects of fucoxanthinol on 3T3-L1 differentiation. Fucoxanthinol attenuated lipid accumulation in 3T3-L1 cells in a dose-dependent manner (Fig. 4). The Oil-Red O staining level of 3T3-L1 cells treated with $10 \mu \mathrm{M}$ fucoxanthinol for

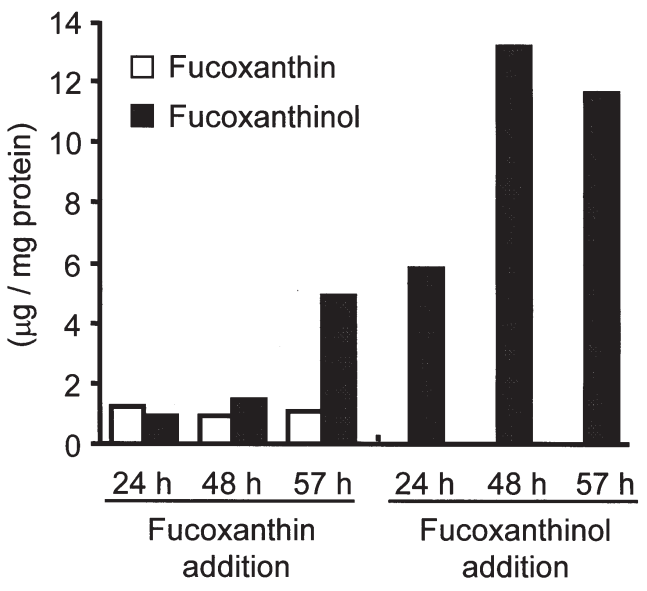

Figure 3. Uptake of fucoxanthin and fucoxanthinol in 3T3-L1 cells during adipocyte differentiation. 3 T3-L1 cells $\left(5 \times 10^{5}\right.$ cells in $100-\mathrm{mm}$ dishes $)$ were incubated with differentiation medium II containing $10 \mu \mathrm{M}$ fucoxanthin or fucoxanthinol for the indicated times, as described in Materials and methods. Carotenoids were extracted with chloroform:methanol $(1: 2, \mathrm{v} / \mathrm{v})$ and analyzed using high performance liquid chromatography. The values are expressed as $\mu \mathrm{g} / \mathrm{mg}$ total cell protein.

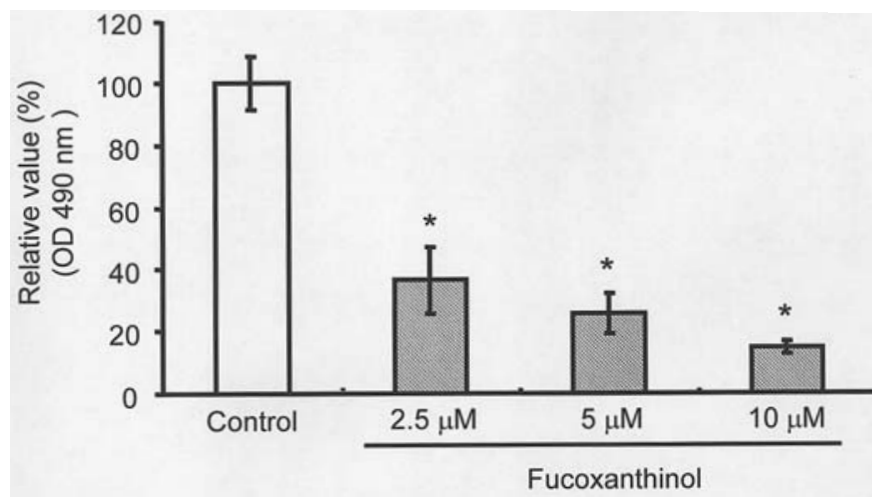

Figure 4. Effect of fucoxanthinol on intercellular lipid accumulation of 3T3-L1 cells induced during adipocyte differentiation. 3T3-L1 cells $\left(5 \times 10^{3}\right.$ cells in 96-well plates) were differentiated to adipocytes as described in Materials and methods. 3T3-L1 cells were treated with fucoxanthinol in differentiation medium II for $120 \mathrm{~h}$. The intercellular lipid accumulation was determined by Oil Red-O staining. The values $(n=3)$ are expressed as absorbance at $490 \mathrm{~nm}$. *Significantly different from the control value $(\mathrm{P}<0.01)$.

$120 \mathrm{~h}$ decreased to $14 \%$ that of control cells, in which adipocyte differentiation was induced without fucoxanthinol.

The effect of fucoxanthinol and fucoxanthin on GPDH activity was also examined as an indicator of 3T3-L1 adipocyte differentiation. In 3T3-L1 cells treated with fucoxanthinol and fucoxanthin, GPDH activity was reduced to a level comparable to that of control cells (Fig. 5). Specifically, the GPDH activity in 3T3-L1 cells treated with 5 and $7.5 \mu \mathrm{M}$ fucoxanthinol for $120 \mathrm{~h}$ was significantly lower than that in 3T3-L1 cells treated with fucoxanthin (Fig. 5). On the other hand, no toxicity was observed in cells treated with up to $10 \mu \mathrm{M}$ fucoxanthinol (data not shown).

Protein expression of PPARy in 3T3-L1 cells treated with fucoxanthin and fucoxanthinol. PPAR $\gamma$ is a major transcriptional factor that regulates the expression of adipogenic genes 


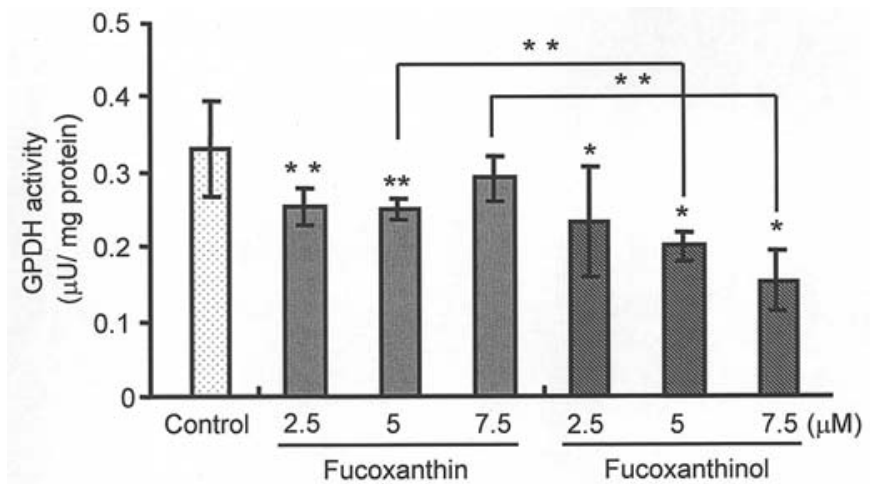

Figure 5. Effect of fucoxanthin and fucoxanthinol on GPDH activity in 3T3-L1 cells induced during adipocyte differentiation. 3T3-L1 cells $\left(2.5 \times 10^{3}\right.$ cells in 24-well plates) were differentiated to adipocytes as described in Materials and methods. 3T3-L1 cells were treated with fucoxanthin or fucoxanthinol in differentiation medium II for $120 \mathrm{~h}$. Intercellular GPDH activity was measured as described in Materials and methods. The values $(n=3)$ are expressed as micro units per milligram total cell protein. Asterisks indicate significantly different values: ${ }^{*} \mathrm{P}<0.01,{ }^{* *} \mathrm{P}<0.05$.
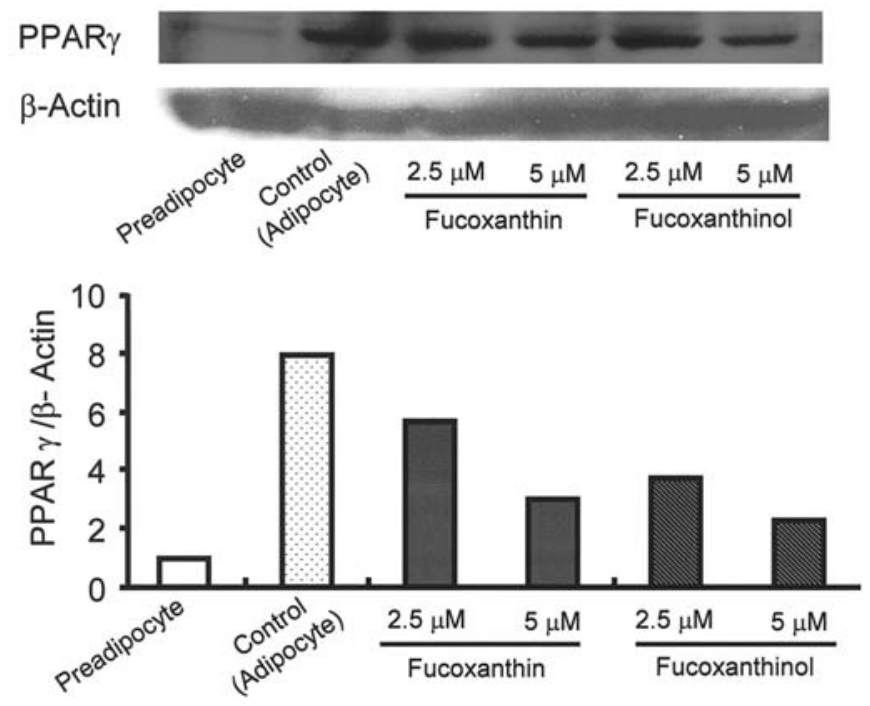

Figure 6. Expression of peroxisome proliferator-activated receptor $\gamma(\operatorname{PPAR} \gamma)$ in 3T3-L1 cells treated with fucoxanthin and fucoxanthinol. 3T3-L1 cells ( $1 \times 10^{5}$ cells in 6-well plates) were differentiated to adipocytes as described in Materials and methods. 3T3-L1 cells were treated with fucoxanthin or fucoxanthinol in differentiation medium II for $120 \mathrm{~h}$. Cellular protein was extracted, and PPAR $\gamma$ protein levels were detected using Western blot analysis and were quantified by densitometry. The PPAR $\gamma$ protein expression level was normalized to the $\beta$-Actin level and expressed as the value relative to preadipocyte PPAR $\gamma$ levels.

and is expressed during the early to middle stage of adipocyte differentiation (20). To investigate the mechanisms underlying fucoxanthin and fucoxanthinol-induced suppression of adipocyte differentiation, the expression of PPAR $\gamma$ protein in 3T3-L1 cells treated with carotenoids was analyzed by Western blotting. PPAR $\gamma$ was markedly induced during adipocyte differentiation (Fig. 6). Fucoxanthinol down-regulated PPAR $\gamma$ in 3T3L1 cells after 120-h incubation. At $5 \mu \mathrm{M}$ fucoxanthinol, the PPAR $\gamma$ expression level decreased to $47 \%$ that of control cells differentiated without carotenoid. Fucoxanthin also down-regulated PPAR $\gamma$ after 120-h incubation.

\section{Discussion}

Fucoxanthin is a carotenoid contained in edible brown seaweeds and is one of the most abundant carotenoids, along with $\beta$-carotene, in nature. Asian people, including Japanese and Koreans, often consume fucoxanthin-rich brown seaweeds such as Undaria pinnatifida and Hijikia fusiformis as a food source. Recently, we demonstrated that fucoxanthin suppressed the weight gain of white adipose tissue in a mouse diabetesobesity model, KK-Ay (16). The incidence of obesity is related with the differentiation of preadipocytes to adipocytes and the enlargement of adipocytes in adipose tissues $(21,22)$. Therefore, we investigated the effects of fucoxanthin on the differentiation of 3T3-L1 cells to clarify the anti-obesity mechanism of dietary fucoxanthin. Fucoxanthin significantly suppressed lipid accumulation in 3T3-L1 cells at a concentration that was not cytotoxic. GPDH activity was decreased in 3T3-L1 cells treated with fucoxanthin compared to control cells incubated in the differentiation medium. Because GPDH is important for triacylglycerol synthesis (23), the present results indicate that fucoxanthin suppresses adipocyte differentiation.

Studies of the uptake and metabolism of fucoxanthin in 3T3-L1 cells indicated that fucoxanthin added to culture medium was incorporated into cells and further converted to fucoxanthinol by deacetylation within $24 \mathrm{~h}$. Fucoxanthinol but not fucoxanthin levels increased in a time-dependent manner. In addition, the carotenoid accumulation in 3T3-L1 cells was greater following treatment with fucoxanthinol than after treatment with fucoxanthin. Sugawara et al (24) and Asai et al (25) also reported that orally administered fucoxanthin is detected as fucoxanthinol and amarouciaxanthin $\mathrm{A}$ in the blood and liver. Therefore, we examined the suppressive effects of fucoxanthinol on 3T3-L1 adipocyte differentiation.

Fucoxanthinol markedly suppressed lipid accumulation during adipocyte differentiation in a dose-dependent manner. Fucoxanthinol (5.0 and 7.5 $\mu \mathrm{M})$ inhibited GPDH activity to a greater extent than fucoxanthin. These results indicate that fucoxanthinol might be the active compound for the antiobesity effect induced in vivo by fucoxanthin administration. It is noteworthy that PPAR $\gamma$ levels were down-regulated in 3T3-L1 cells treated with fucoxanthinol and fucoxanthin. PPAR $\gamma$ has an important role in the early stages of 3T3-L1 cell differentiation $(26,27)$ because it is a nuclear transcription factor that regulates adipogenic gene expression (20). These results indicate that fucoxanthin and fucoxanthinol suppress the differentiation of preadipocytes to adipocytes in 3T3-L1 cells and their suppressive effect is, at least, one mechanism underlying the anti-obesity effect of dietary fucoxanthin. Some other natural compounds and extracts, including catechin (28), sterols (29), tannic acid (30), phenolic lipids (31) and red yeast rice extracts (32), also inhibit 3T3-L1 differentiation. Retinoids also inhibit the early stage of differentiation of 3T3-L1 cells (33). Some of these compounds and extracts, however, have low absorption and have not been investigated for their anti-obesity effects in vivo. Because fucoxanthin accumulates as metabolites, including fucoxanthinol, in white adipose tissue of mice (data not shown), dietary fucoxanthin might be a useful natural compound for the prevention of obesity. 
Uncoupling protein 1 (UCP1) is expressed in the white adipose tissue of mice fed diets including fucoxanthin (16). UCP1 is a key molecule for metabolic thermogenesis for avoiding excessive fat accumulation (34), and the expression of UCP1 mRNA is regulated by PPAR $\gamma(35)$ and $B$-adrenergic receptors (36). The relationship between UCP1 up-regulation and PPAR $\gamma$ down-regulation, however, is not clear. Fucoxanthin and fucoxanthinol might have multiple suppressive effects on obesity. Further investigation is needed to elucidate the mechanisms underlying fucoxanthin's anti-obesity effects.

In conclusion, fucoxanthin, found in edible brown seaweeds, suppressed the differentiation of 3T3-L1 preadipocytes to adipocytes. Fucoxanthin was incorporated and converted to fucoxanthinol in 3T3-L1 cells. The metabolite, fucoxanthinol, also exhibited suppressive effects on 3T3-L1 differentiation through PPAR $\gamma$ down-regulation. These findings indicate that diets containing fucoxanthin might prevent obesity through the suppression of adipocyte differentiation.

\section{Acknowledgements}

This study was partially supported by the Grant-in-Aid for Scientific Research and the 21st century COE Program 'Marine Bio-Manipulation Frontier for Food Production' of Ministry of Education, Culture, Sports, Science and Technology of Japan.

\section{References}

1. Spiegelman BM and Flier JS: Adipogenesis and obesity: rounding out the big picture. Cell 87: 377-389, 1996.

2. Fruhbeck G, Gomez-Ambrosi J, Muruzabal FJ and Burrell MA: The adipocyte: a model for integration of endocrine and metabolic signaling in energy metabolism regulation. Am J Physiol Endocrinol Metab 280: 827-847, 2001.

3. Gregoire FM: Adipocyte differentiation: from fibroblast to endocrine cell. Exp Biol Med 226: 997-1002, 2001.

4. Kopelman PG: Obesity as a medical problem. Nature 404: 635-643, 2000

5. Visscher TL: The public health impact of obesity. Annu Rev Public Health 22: 355-375, 2001.

6. Faure H, Fayol V, Galabert C, Grolier P, Le Moel G, Steghens JP, van Kappel A and Nabert F: Carotenoids: 1. Metabolism and physiology. Ann Biol Clin 57: 169-183, 1999.

7. Berhard K, Moss GP, Toth GY and Weedon BCL: Absolute configuration of fucoxanthin. Tetrahedron Lett 17: 115-118, 1976.

8. Satomi Y, Tokuda H, Fujiki H, Shimizu N, Tanaka Y and Nishino H: Anti-tumor-promoting activity of fucoxanthin, a natural carotenoid. J Kyoto Pref Univ Med 105: 739-743, 1996.

9. Kim JM, Araki S, Kim DJ, Park CB, Takasuka N, BabaToriyama H, Ota T, Nir Z, Khachik F, Shimidzu N, Tanaka Y, Osawa T, Uraji T, Murakoshi M, Nishino $\mathrm{H}$ and Tsuda $\mathrm{H}$ : Chemopreventive effects of carotenoids and curcumins on mouse colon carcinogenesis after 1,2-dimethylhydrazine initiation. Carcinogenesis 19: 81-85, 1998.

10. Okuzumi J, Nishino H, Murakoshi M, Iwashima A, Tanaka Y, Yamane T, Fujita Y and Takahashi T: Inhibitory effects of fucoxanthin, a natural carotenoid, on N-myc expression and cell cycle progression in human malignant tumor cells. Cancer Lett 55: 75-81, 1990 .

11. Hosokawa M, Wanezaki S, Miyauchi K, Kurihara H, Kohno H, Kawabata J, Odashima S and Takahashi K: Apoptosis-inducing effect of fucoxanthin on human leukemia cell HL-60. Food Sci Technol Res 5: 243-246, 1999.

12. Kotake-Nara E, Kushiro M, Zhang H, Sugawara T, Miyashita K and Nagao A: Carotenoids affect proliferation of human prostate cancer cells. J Nutr 131: 3303-3306, 2001.
13. Hosokawa M, Kudo M, Maeda H, Kohno H, Tanaka T and Miyashita K: Fucoxanthin induces apoptosis and enhances the antiproliferative effect of the PPARgamma ligand, troglitazone, on colon cancer cells. Biochim Biophys Acta 1675: 113-119, 2004.

14. Shiratori K, Ohgami K, Ilieva I, Jin XH, Koyama Y, Miyashita K, Kase S and Ohno S: Effects of fucoxanthin on lipopolysaccharide-induced inflammation in vitro and in vivo. Exp Eye Res 81: 422-428, 2005.

15. Nomura T, Kikuchi M, Kubodera A and Kawakami Y: Protondonative antioxidant activity of fucoxanthin with 1,1-diphenyl2-picrylhydrazyl (DPPH). Biochem Mol Biol Int 42: 361-370, 1997.

16. Maeda H, Hosokawa M, Sashima T, Funayama K and Miyashita K: Fucoxanthin from edible seaweed, Undaria pinnatifida, shows antiobesity effect through UCP1 expression in white adipose tissues. Biochem Biophys Res Commun 332: 392-397, 2005.

17. Ishiyama M, Shiga M, Sakamoto K, Mizoguchi M and He PA New sulfonated tetrazolium salt that produces a highly watersoluble formazan dye. Chem Pharm Bull 41: 1118-1122, 1993.

18. Evans M, Geigerman C, Cook J, Curtis L, Kuebler B and McIntosh M: Conjugated linoleic acid suppresses triglyceride accumulation and induces apoptosis in 3T3-L1 preadipocytes. Lipids 35: 899-910, 2000.

19. Kawada T, Aoki N, Kamei Y, Maeshige K, Nishiu S and Sugimoto E: Comparative investigation of vitamins and their analogues on terminal differentiation, from preadipocytes to adipocytes, of 3T3-L1 cells. Comp Biochem Physiol A 96: 323-326, 1990.

20. Paul AG: The roles of PPARs in adipocyte differentiation. Prog Lipid Res 40: 269-281, 2001.

21. Shimomura I, Funahashi T, Takahashi M, Maeda K, Kotani K, Nakamura T, Yamashita S, Miura M, Fukuda Y, Takemura K, Tokunaga K and Matsuzawa Y: Enhanced expression of PAI-1 in visceral fat: possible contributor to vascular disease in obesity. Nat Med 2: 800-803, 1996.

22. Okuno A, Tamemoto H, Tobe K, Ueki K, Mori Y, Iwamoto K, Umesono K, Akanuma Y, Fujiwara T, Horikoshi H, Yazaki Y and Kadowaki T: Troglitazone increases the number of small adipocytes without the change of white adipose tissue mass in obese zucker rats. J Clin Invest 101: 1354-1361, 1998.

23. Wise LP and Green H: Participation of one isozyme of cytosolic glycerophosphate dehydrogenase in the adipose conversion of 3T3 cells. J Biol Chem 254: 273-275, 1979.

24. Sugawara T, Baskaran V, Tsuzuki W and Nagao A: Brown algae fucoxanthin is hydrolyzed to fucoxanthinol during absorption by Caco-2 human intestinal cells and mice. J Nutr 132: 946-951, 2002.

25. Asai A, Sugawara T, Ono H and Nagao A: Biotransformation of fucoxanthinol into amarouciaxanthin A in mice and HepG2 cells: formation and cytotoxicity of fucoxanthin metabolites. Drug Metab Dispos 32: 205-211, 2004.

26. Gregorie FM, Smas CM and Sul HS: Understanding adipocyte differentiation. Physiol Rev 78: 783-809, 1998.

27. Tontonoz P, Hu E and Spiegelman BM: Stimulation of adipogenesis in fibroblasts by PPAR gamma 2, a lipid-activated transcription factor. Cell 79: 1147-1156, 1994.

28. Furuyashiki T, Nagayasu H, Aoki Y, Bessho H, Hashimoto T, Kanazawa $\mathrm{K}$ and Ashida $\mathrm{H}$ : Tea catechin suppresses adipocyte differentiation accompanied by down-regulation of PPAR gamma 2 and C/EBPalpha in 3T3-L1 cells. Biosci Biotechnol Biochem 68: 2353-2359, 2004

29. Awad AB, Begdache LA and Fink CS: Effect of sterols and fatty acids on growth and triglyceride accumulation in 3T3-L1 cells. J Nutr Biochem 11: 153-158, 2000.

30. Liu X, Kim JK, Li Y, Liu F and Chen X: Tannic acid stimulates glucose transport and inhibits adipocyte differentiation in 3T3-L1 cells. J Nutr 135: 165-171, 2005.

31. Rejman J and Kozubek A: Inhibitory effect of natural phenolic lipids upon NAD-dependent dehydrogenases and on triglyceride accumulation in 3T3-L1 cells in culture. J Agric Food Chem 52: 246-250, 2004.

32. Jeon T, Hwang SG, Hirai S, Matsui T, Yano H, Kawada T, Lim BO and Park DK: Red yeast rice extracts suppress adipogenesis by down-regulating adipogenic transcription factors and gene expression in 3T3-L1 cells. Life Sci 75: 3195-3203, 2004 . 
33. Kawada T, Kamei Y, Fujita A, Hida Y, Takahashi N, Sugimoto E and Fushiki T: Carotenoids and retinoids as suppressors on adipocyte differentiation via nuclear receptors. Biofactors 13: 103-109, 2000.

34. Lowell BB, S-Susulic V, Hamann A, Lawitts JA, Himms-Hagen J, Boyer BB, Kozak LP and Flier JS: Development of obesity in transgenic mice after genetic ablation of brown adipose tissue. Nature 6: 740-742, 1993.
35. Foellmi-Adams LA, Wyse BM, Herron D, Nedergaard J and Kletzien RF: Induction of uncoupling protein in brown adipose tissue. Synergy between norepinephrine and pioglitazone, an insulin-sensitizing agent. Biochem Pharmacol 52: 693-701, 1996.

36. Lowell BB and Spiegelman BM: Towards a molecular understanding of adaptive thermogenesis. Nature 404: 652-660, 2000 . 